\title{
MEDICAL CO-MORBID CONDITIONS ASSOCIATED WITH PSORIASIS; PSORIASIS BEYOND SKIN.
}

1. MBBS, FCPS (Dermatology) Consultant Dermatologist DHQ Hospital Multan.

2. MBBS, FCPS (Dermatology) Assistant Professor Dermatology Rawal Institute of Health Sciences Islamabad.

3. MBBS, FCPS (Medicine) Associate Professor Medicine Rawal Institute of Health Sciences Islamabad.

4. MD, MCPS (Dermatology) Senior Registrar Akbar Niazi Teaching Hospital Islamabad.

5. MBBS, FCPS (Dermatology) Associate Professor Dermatology Karachi Institute of Medical Sciences.

Correspondence Address:

Dr. Mahvish Aftab Khan

H \# 880, Street \# 27, G-9/1, Islamabad.

mehvishmuddasser@yahoo.com

Article received on:

20/02/2019

Accepted for publication:

25/08/2019

\begin{abstract}
Sehrish Aftab', Mahvish Aftab Khan ${ }^{2}$, Nadia Shams ${ }^{3}$, Sumaira Abdullah', Furquana Niaz $^{5}$
\end{abstract}
ABSTRACT... Objectives: Patients with psoriasis have higher prevalence of associated medical disorders including psoriatic arthritis, obesity, diabetes, dyslipidemia, thyroid abnormalities and cardiovascular disease. The rationale of current study was to determine prevalence of associated medical co-morbid conditions in psoriasis cases. Study Design: Descriptive cross sectional study. Setting: Dermatology Clinic, Bahawalpur Victoria Hospital. Period: January to July 2015. Material \& Methods: Informed consent was obtained from 117 adult patients (>18 years) of both the genders diagnosed with psoriasis for $>3$ months. Patients with chronic renal failure, chronic liver disease, erythroderma, chromosomal abnormality syndromes and pregnant females were excluded. Blood pressure and body mass index; i.e. BMI=weight (kg)/ height $\left(\mathrm{m}^{2}\right)$ were documented. Fasting blood sugars, $\mathrm{HbA} 1 \mathrm{c}$, lipid profile and electrocardiogram was done. Results: Mean age was $41.94 \pm 11.60$ years. Among 117 cases, 66(56.41\%) were males and $51(43.59 \%)$ were females; male to female ratio was 1.3:1. Diabetes mellitus was found in $53(45.30 \%)$, hypertension in $21(17.95 \%)$, obesity in $29(24.79 \%)$, ischemic heart disease in $62(52.99 \%)$ and dyslipidemia in $22(18.80 \%)$ patients. Conclusion: Current study concludes that patients with psoriasis have higher prevalence of ischemic heart disease and diabetes mellitus followed by obesity, dyslipidemia and hypertension. It is suggested that psoriasis cases presenting to dermatology department should be assessed for these co-morbid conditions for early diagnosis and management of these conditions.

Key words: Diabetes Mellitus, Dyslipidemia, Hypertension, Obesity, Psoriasis.

Article Citation: Aftab S, Khna MA, Shams N, Abdullah S, Niaz F. Medical co-morbid conditions associated with psoriasis; psoriasis beyond skin. Professional Med J 2020; 27(3):511-516. DOI: 10.29309/TPMJ/2020.27.3.3302

\section{INTRODUCTION}

Psoriasis is a chronic inflammatory condition of skin that involves immune mechanism. It is characterized by red, scaly patches, papules or plaques, which present with the complaint of itching. ${ }^{1}$ The severity of the skin lesions in psoriasis may manifest as minor localized patches to extensive psoriasis with involvement of almost complete body. 2,3 Psoriasis has been reported to affect approx. $2 \%$ of world's population. ${ }^{4}$ The five main types of psoriasis are plaque, guttate, inverse, pustular and erythrodermic psoriasis. The most common form is Plaque psoriasis characterized by sharply demarcated and erythematous areas covered with silvery white scales. ${ }^{5}$ Psoriasis is a systemic illness and manifestations of psoriasis extend beyond the skin. ${ }^{6}$ Epidemiological studies have reported psoriasis is frequently associated with systemic disorders. In addition to psoriatic arthritis, the frequently seen medical conditions are obesity, diabetes, dyslipidemia, thyroid abnormalities and cardiovascular disease. ${ }^{7}$ The causal relationship between psoriasis and the medical co-morbids hasn't been proved, however it has been suggested that chronic inflammation and pro-inflammatory cytokines are the contributory factors. Along with the increase in age, these factors are also considered to rise. Approx. $2 / 3^{\text {rd }}$ of psoriasis patients have two or more co-morbid conditions, this has significant on mortality, morbidity and the health care dependency in psoriasis cases. ${ }^{8,9}$

In order to improve the quality of life of psoriasis patients, physicians should be aware of the associations of psoriasis to provide extensive medical care to psoriasis patients. There should be an integrated approach in treating psoriasis 
and associated co-morbids. The rationale of current study was to determine the prevalence of medical co-morbid conditions in patients with psoriasis in regional population. The results of this study will be helpful to reduce the morbidity in psoriasis patients by recommending the practical implications for proper screening and management of medical co-morbid conditions in psoriasis cases.

\section{MATERIALS AND METHODS}

This descriptive, cross sectional study was conducted at dermatology outdoor clinic, Bahawalpur Victoria Hospital after approval by ethical review board of hospital from January to July 2015. Total 117 adult patients (>18 years) of both the genders with diagnosis of psoriasis for $>3$ months duration meeting the inclusion criteria were selected by non-probability consecutive sampling after informed consent. The sample size of 117 cases was calculated with 95\% confidence level, $6 \%$ margin of error and expected frequency of medical co-morbid conditions in psoriasis as $12.5 \% .{ }^{10}$

Patients with chronic renal failure, chronic liver disease, erythroderma, chromosomal abnormality syndromes and pregnancy were excluded.

All patients were evaluated for presence of any medical comorbid conditions. Blood sample was sent for fasting blood sugar, Glycosylated hemoglobin (HbA1c) and lipid profile for presence or absence of diabetes mellitus and dyslipidemia respectively. Blood pressure was checked by the researcher themself at two different occasions for presence of hypertension. BMI was calculated by following formula; BMI = weight $(\mathrm{kg})$ / height $\left(\mathrm{m}^{2}\right)$ and obesity was noted as present or absent. Electrocardiography and cardiac evaluation was done for ischemic heart disease.

Statistical analysis was performed using SPSS version 20. Results were presented as mean and standard deviation for quantitative variables (i.e. age and duration of disease). For qualitative variables frequency and percentages were calculated. Effect modifiers like age, gender, duration of disease and family history of psoriasis (yes/no) were controlled through stratifications. Post-stratification chi square was applied to see the effect of these on frequency of co-morbid conditions and p-value $\leq 0.05$ was taken as statistically significant.

\section{RESULTS}

Among 117 cases, mean age was $41.94 \pm 11.60$ years with a range of 20-60 years. Majority of the patients presenting with psoriasis, i.e. 64(54.70\%) were $<40$ years age and 53(45.30\%) were above 40 years age. The age group above 40 years was found to be significantly associated with presence of ischemic heart disease $(p<0.0001)$ and dyslipidemia $(p=0.018)$; however diabetes mellitus, hypertension and obesity was not found to be associated with age above 40 years in psoriasis cases ( $p>0.05$, Table-I).

There were 66(56.41\%) males and 51(43.59\%) females with male to female ratio of 1.3:1. Gender was not found to be associated with diabetes, hypertension, obesity or dyslipidemia in psoriasis cases ( $p>0.05)$; however male patients presenting with psoriasis had significantly high frequency of ischemic heart disease i.e. 43(65.15\%) among males vs. $19(37.25 \%)$ among female psoriasis cases $(p=0.003$; Table-l).

Mean duration of the disease was $6.30 \pm 3.09$ months. There were $76(64.96 \%)$ cases with duration of psoriasis < 6 months and 41 (35.04\%) with duration $>6$ months. Duration of psoriasis was not found to be associated with any of the studied medical co-morbid conditions $(p>0.05$; Table-I)

The family history of psoriasis was positive in in $69(58.97 \%)$ psoriasis cases. Family history of psoriasis was not found to be associated with presence of the studied medical co-morbid conditions ( $p>0.05$; Table-I).

Diabetes mellitus was found in 53(45.30\%), hypertension in $21(17.95 \%)$, obesity in 29 (24.79\%), ischemic heart disease in 62 (52.99\%) and dyslipidemia in 22 (18.80\%) patients (Figure-1). 


\begin{tabular}{|c|c|c|c|c|c|c|}
\hline & $\begin{array}{l}\text { Among all } \\
(n=117)\end{array}$ & $\begin{array}{l}\text { Diabetes Mellitus } \\
\qquad(n=53)\end{array}$ & $\begin{array}{l}\text { Hypertension } \\
(n=21)\end{array}$ & $\begin{array}{l}\text { Obesity } \\
(n=39)\end{array}$ & $\begin{array}{c}\text { Ihd } \\
(n=62)\end{array}$ & $\begin{array}{c}\text { Dys-lipidemia } \\
\qquad(n=22)\end{array}$ \\
\hline \multirow{2}{*}{$\begin{array}{l}\text { Age } \\
<40 \text { years } \\
>40 \text { years }\end{array}$} & \multirow{2}{*}{$\begin{array}{l}64(54.70 \%) \\
53(45.29 \%)\end{array}$} & $\begin{array}{l}25(39.06 \%) \\
28(52.83 \%)\end{array}$ & $\begin{array}{l}10(15.63 \%) \\
11(20.75 \%)\end{array}$ & $\begin{array}{l}17(26.56 \%) \\
12(22.64 \%)\end{array}$ & $\begin{array}{l}21(32.81 \%) \\
41(77.36 \%)\end{array}$ & $\begin{array}{l}17(11.39 \%) \\
05(26.56 \%)\end{array}$ \\
\hline & & ${ }^{* *} p=0.136$ & ${ }^{*} p=0.472$ & ${ }^{* *} p=0.635$ & ${ }^{*} \mathrm{p}=<0.0001$ & ${ }^{* *} p=0.018$ \\
\hline $\begin{array}{l}\text { Gender } \\
\text { Male } \\
\text { Female }\end{array}$ & $\begin{array}{l}66(56.41 \%) \\
51(43.58 \%)\end{array}$ & $\begin{array}{l}30(45.45 \%) \\
23(45.10 \%)\end{array}$ & $\begin{array}{l}14(21.21 \%) \\
07(13.73 \%)\end{array}$ & $\begin{array}{l}17(27.27 \%) \\
11(21.57 \%)\end{array}$ & $\begin{array}{l}43(65.15 \%) \\
19(37.25 \%)\end{array}$ & $\begin{array}{l}16(24.24 \%) \\
06(11.76 \%)\end{array}$ \\
\hline \multirow{2}{*}{$\begin{array}{l}\text { Duration } \\
<6 \text { months } \\
>6 \text { months }\end{array}$} & \multirow{2}{*}{$\begin{array}{l}76(64.95 \%) \\
41(35.04 \%)\end{array}$} & $\begin{array}{l}38(50.00 \%) \\
15(36.59 \%)\end{array}$ & $\begin{array}{l}11(14.47 \%) \\
10(24.39 \%)\end{array}$ & $\begin{array}{l}19(25.00 \%) \\
10(24.39 \%)\end{array}$ & $\begin{array}{l}37(48.68 \%) \\
25(60.98 \%)\end{array}$ & $\begin{array}{l}14(18.42 \%) \\
08(19.51 \%)\end{array}$ \\
\hline & & ${ }^{* *} p=0.164$ & ${ }^{* *} p=0.182$ & ${ }^{* *} p=0.942$ & ${ }^{* *} p=0.204$ & ${ }^{* *} p=0.885$ \\
\hline $\begin{array}{l}\text { Family history } \\
\text { Yes } \\
\text { No }\end{array}$ & $\begin{array}{l}69(58.97 \%) \\
48(41.02 \%)\end{array}$ & $\begin{array}{l}28(40.58 \%) \\
25(52.08 \%)\end{array}$ & $\begin{array}{l}13(18.84 \%) \\
08(16.67 \%)\end{array}$ & $\begin{array}{l}18(26.09 \%) \\
11(22.92 \%)\end{array}$ & $\begin{array}{l}38(55.07 \%) \\
24(50.00 \%)\end{array}$ & $\begin{array}{l}10(14.49 \%) \\
12(25.00 \%)\end{array}$ \\
\hline
\end{tabular}

Table-I. (test of significance $=8 \mathrm{Chi}$-square test; $* *$ student t-test; significant $\mathrm{p}<0.05$ ).

Frequency of medical co-morbid conditions

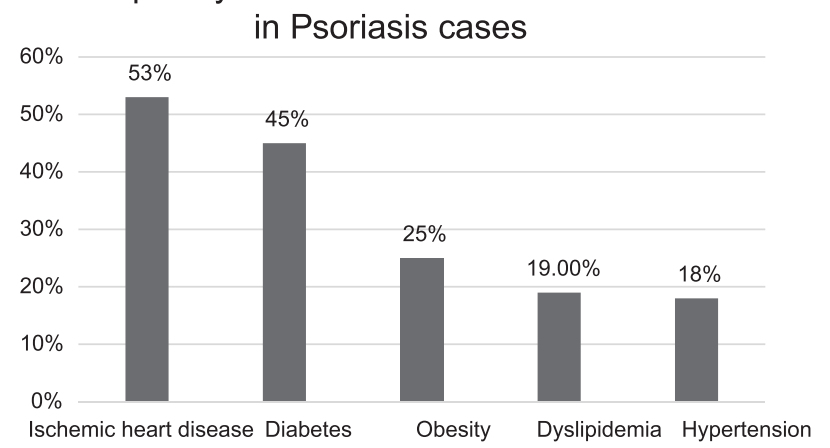

Figure-1. Bar graph presentation of medical co-morbid conditions in Psoriasis cases $(n=117)$.

Table-I. Stratification of Diabetes, hypertension, obesity, dyslipidemia and ischemic heart disease (IHD) in psoriasis cases with respect to age, gender, duration and family history of psoriasis.

\section{DISCUSSION}

Psoriasis has been found to be associated with high percentage of co-morbid conditions i.e. diabetes mellitus, stroke and cardiovascular disease in several observational studies. The psoriasis cases receiving systemic treatment or phototherapy have higher prevalence of these medical co-morbid conditions and this association is independent of the conventional risk factors for these outcomes. Associations with other comorbid diseases, such as metabolic syndrome, chronic obstructive pulmonary disease, asthma, acid peptic disease, liver disease, renal failure, and rheumatoid arthritis, have also been reported by certain studies. ${ }^{11}$ Hence, current study was conducted to determine the prevalence of medical co-morbid conditions in patients with psoriasis.

The mean age of patients in this study was 41.94 \pm 11.60 years with more than half of the cases (54.7\%) were between 20-40 years age. Lin TY et $\mathrm{al}^{12}$ and $\mathrm{Al}$-Abdulrazzaq $\mathrm{A}$ et $\mathrm{al}^{13}$ in their studies have found mean age of 42 years which is very much comparable to our study. Contrary to this, Austin $\mathrm{M}$ et $\mathrm{al}^{14}$ in his study have found higher mean age of 50 years as compared to our study. Also, Shahin A et $\mathrm{al}^{15}$ has shown comparatively lower mean age of 34 years. In current study, out of 117 patients, $56.41 \%$ were males and $43.59 \%$ were females with male to female ratio of 1.3:1. Many previous studies have also shown male predominance as observed in our study. ${ }^{12-15}$

A Swedish study conducted by David Hagg ${ }^{16}$ from Umea University addressed the association of gender with biologics treatment in psoriasis. It was observed that males are more likely to be prescribed biologics possibly because of increased severity of psoriasis in males as compared to females. The other reason could be the discriminatory approach in for male versus female cases rather than the severity of psoriasis itself. This study raised a question that whether or not men were more likely to receive high priced biologics than women because more than half (i.e.59\%) of the registered patients were men. 
In our study, prevalence of diabetes mellitus was found in approx. half of the cases, i.e. $45.3 \%$. Hypertension was found in $17.95 \%$, obesity in $24.79 \%$, ischemic heart disease in $53 \%$ and dyslipidemia in $19 \%$ of psoriasis cases. In the study conducted by Thomas $\mathrm{J}$ et al, 55.8\% patients had some comorbid condition associated. ${ }^{17}$ An Indian study conducted by the same authors ${ }^{18}$ showed that total $52 \%$ of patients had some associated comorbidity in their study. Both of these Indian studies were hospital based and the dyslipidemia sample included both male and female patients. In a study conducted by Kumar $\mathrm{P}$ et $\mathrm{al}^{19}, 200$ patients of psoriasis were studied and a total of $88.5 \%$ patients had one or more comorbid conditions i.e. obesity in $22.5 \%$, diabetes in $49 \%$, in $14.5 \%$, hypertension in $12.5 \%$. Psoriasis is also found to be associated with an increased risk of cardiovascular disease and $56 \%$ increase in ischemic heart disease. ${ }^{20}$

There is increased the risk of diabetes in psoriasis cases independent of the other risk factors i.e. weight, hypertension and hypercholesterolemia. A psoriasis patient is $59 \%$ more likely to be diagnosed with diabetes and a patient with severe psoriasis is even $97 \%$ more likely to be diagnosed with diabetes as compared to those without psoriasis which was found out by a study in 2012. There is a marked reduction in the life expectancy of psoriatic individuals diagnosed with diabetes. It has also been estimated that if an individual is diagnosed at an age of 40 years, men will lose 11.6 life-years (18.6 quality-adjusted life-years) and women will lose 14.3 life-years (22.0 quality-adjusted life-years). The association between diabetes mellitus and psoriasis had been suggested well before in year 1908. Qureshi et $\mathrm{al}^{21}$ documented, in their prospective study of female nurses, the link between psoriasis and both diabetes mellitus and hypertension. Hence, psoriasis is associated with significant comorbidities that indicate an elevated risk of severe complications, which is quite frequently observed. ${ }^{22}$

Palmo-plantar psoriasis was the most common type in an Indian study conducted by Thomas et al., with maximum number of patients in age group of 41-50 years. More than half of patients had the disease for a period of 1-5 yrs. Diabetes mellitus was seen in $11.6 \%$ of patients and hypertension in $14.1 \%$. Both diabetes and hypertension were seen in $12.5 \%$ of patients; $6.6 \%$ of patients were obese. In $4.1 \%$ of patients, lipid profile was found to be deranged.

Obesity and psoriasis have proven association, with their correlation originally proposed more than ten years ago by Henseler and Christophe. ${ }^{23}$ This was later reinforced by multiple large clinical trials, reviews, and cohort studies. Obesity is defined as a body mass index (BMI) above 30. A study conducted upon 10,000 patients with moderate-to-severe psoriasis, showed an average BMl of $30.6 \mathrm{~kg} / \mathrm{m}^{2}{ }^{24}$ In addition, almost half i.e. $46 \%$ of patients with moderate-to-severe psoriasis were obese which was revealed by a study on 3700 etanercept clinical trial patients. Similarly, the Utah Psoriasis Initiative (UPI) study showed a higher prevalence of obesity, i.e almost double in the psoriatic population as compared to general population (34\% vs.18\%; $p=0.001$ ), proving strong association between psoriasis and obesity. A positive correlation between obesity grades and severity of psoriasis also was demonstrated in the UPI study. Whether this association applies to full spectrum of psoriasis patients or only those with more severe psoriasis is still uncertain and needs to be studied further.

Obesity, as measured by waist circumference, is an important component of the metabolic syndrome along with impaired glucose metabolism, raised triglycerides, reduced highdensity lipoprotein and hypertension. Metabolic syndrome was significantly common in psoriasis patients than in controls $(30.1 \%$ Vs. $20.6 \%)$ as indicated by a hospital based case-control study. ${ }^{25}$ As per authors, understanding of the health risks attributed to the metabolic syndrome, these findings indicate that psoriasis is likely to have an impact on cardiovascular morbidity and mortality in psoriasis patients by contributing to greater risk compared with the general population for coronary heart disease, myocardial infarction, stroke, and type 2 diabetes mellitus. ${ }^{26}$ 
The psoriasis cases were found to have raised serum lipids; this was initially reported by Lea Cornish and Block. ${ }^{27}$ Since then, several studies have been conducted on this subject that have reported a raised prevalence of lipid abnormalities in psoriasis. ${ }^{28,29}$ There may be multiple reasons for dyslipidemia in patients with psoriasis. The factors contributing to altered lipid metabolism are structural and functional changes in digestive tract, immune mechanisms involving IL-624, tumor necrosis factor, C-reactive proteins and cellular oxidative stress.

The results of current study will be helpful to provide regional data of co-morbids in psoriasis cases that may be compared to international figures. This will be helpful to assess the comorbid conditions in our patients with psoriasis. Hence, leading to a more integrated and multilevel approach to address these risk factor's prevention and management for better outcome in psoriasis cases. Results of current study should be interpreted carefully and authors recommend further regional studies with improved sample size and analysis of other possible co-morbids also.

\section{CONCLUSION}

Current study concludes that patients with psoriasis have high frequency of ischemic heart disease and diabetes mellitus followed by obesity, dyslipidemia and hypertension. Authors recommend the screening and evaluation of these co-morbid conditions in patients presenting with psoriasis. The timely diagnosis and appropriate management of these medical comorbid conditions in psoriasis cases may lead to reduced morbidity and improved outcome.

Copyright@ 25 Aug, 2019.

\section{REFERENCES}

1. Menter A, Gottlieb A, Feldman SR, Van Voorhees AS, Leonardi CL, Gordon KB, et al. Guidelines of care for the management of psoriasis and psoriatic arthritis: Section 1. Overview of psoriasis and guidelines of care for the treatment of psoriasis with biologics. J Am Acad Dermatol. 2008; 58(5):826-50.
2. Lewis-Beck C, Abouzaid S, Xie L, Baser O, Kim E. Analysis of the between psoriasis symptom severity and quality of life, work productivity, and activity impairment among patients with moderate-to-severe psoriasis using structural equation modeling. Patient Prefer Adherence. 2013; 7:199-205.

3. Khan GA, Malik LM, Jahangir M. Prevalence of smoking, alcohol and co-morbid conditions in psoriasis. JPAD. 2010; 20(4):212-6.

4. Tang MM, Chang CC, Chan LC, Heng A. Quality of life and cost of illness in patients with psoriasis in Malaysia: a multicenter study. Int J Dermatol. 2013; 52(3):314-22.

5. Ali ME, Rehman GMM, Akhter N, Wahab MA, Rashid MM, Islam AZMM. Efficacy and safety of leflunomide in the treatment of plaque type psoriasis. JPAD. 2009; 19(1):18-22.

6. Husted JA. Cardiovascular and other comorbidities in patients with psoriasis. Arthritis Care Res. 2011; 63:1729-35.

7. Naldil, Mercuri SR. Epidemiology of co-morbidities in psoriasis. Dermatol ther. 2010; 23:114-8.

8. Gulliver WP. Importance of screening for comorbidities in psoriasis patients. Expert Rev Dermatol. 2008; 3:133-35.

9. Jama $Y$. Psoriasis patients had significant associations with co-morbid diseases. J Dermatol. 2013; 50:15.

10. Parisi R, Symmons DP, Griffiths CE, Ashcroft DM. Global epidemiology of psoriasis: a systematic review of incidence and prevalence. J Invest Dermatol. 2013; 133(2):377-85.

11. Langan SM, Seminara NM, Shin DB. Prevalence of metabolic syndrome in patients with psoriasis: a population-based study in the United Kingdom. J Invest Dermatol. 2012; 132(3):556-62.

12. Lin TY, See LC, Shen YM, Liang CY, Chang HN, Lin YK. Quality of life in patients with psoriasis in northern Taiwan. Chang Gung Med J. 2011; 34(2):186-96.

13. Al-Abdulrazzaq A, Zadeh VB, Al-Otaibi S, Tarrab S, Najem N. Treatment of psoriasis with etanercept: an experience from South Kuwait. J Pak Assoc Dermatol. 2012; 22:136-45.

14. Austin M, Kruger K, Radtke MA, Schwippl I, Reich K. Disease Severity, Quality of Life and Health Care in Plaque-Type Psoriasis: A Multicenter CrossSectional Study in Germany. Dermatology. 2008; 216:366-72. 
15. Shahin A, Ahmad M, Safaee AG. Impact of psoriasis on quality of life in Iran. Indian J Dermatol Venereol Leprol. 2009; 75(2):220.

16. Hägg D, Eriksson M, Sundström A, Schmitt-Egenolf $M$. The higher proportion of men with psoriasis treated with biologics may be explained by more severe disease in men. PLoS One. 2013; 8(5):e63619. Published 2013 May 15. doi:10.1371/journal. pone.0063619

17. Thomas J, Ashok Kumar N, Manoharan D. A study of co morbid conditions in psoriasis. J Pak Assoc Dermatol. 2009; 19:200-2.

18. Thomas J, Ashok Kumar N, Manoharan D, Ashwak Ahamed N. Co morbid conditions associated with psoriasis. J Indian Soc Teledermatol. 2010; 4:1-5.

19. Kumar P, Thomas J. Comorbid conditions in psoriasis - Higher frequency in females: a prospective study. Indian Dermatol Online J. 2012; 3(2):105-8.

20. Mehta NN, Yu Y, Pinnelas R, Krishnamoorthy P, Shin DB, Troxel $A B$, et al. Attributable risk estimate of severe psoriasis on major cardiovascular events. Am J Med. 2011; 124(8):775.e1-6.

21. Qureshi AA, Choi HK, Setty AR, Curhan GC. Psoriasis and the Risk of Diabetes and Hypertension: $A$ Prospective Study of US Female Nurses. Arch Dermatol. 2009; 145:379-82.
22. Augustin M, Reich K, Glaeske G, Glaeske G, Schaefer I, Radtke M. Co-morbidity and Age-related Prevalence of Psoriasis: Analysis of Health Insurance Data in Germany. Acta Derm Venereol. 2010; 90:147-51.

23. Henseler T, Christophers E. Disease concomitance in psoriasis. J Am Acad Dermatol. 1995; 32:982-86.

24. Sterry W, Strober BE, Menter A. Obesity in psoriasis: The metabolic, clinical and therapeutic implications. Report of an interdisciplinary conference and review. Br J Dermatol. 2007; 157:649-55.

25. Sterry W, Strober BE, Menter A. Obesity in psoriasis: The metabolic, clinical and therapeutic implications. Report of an interdisciplinary conference and review. Br J Dermatol. 2007; 157:649-55.

26. Shirai K. Obesity as the core of the metabolic syndrome and the management of coronary heart disease. Curr Med Res Opin. 2004; 20:295-304.

27. Lea WA Jr, Cornish HH, Block ED. Studies on serum lipids, proteins and lipoproteins in psoriasis. J Invest Dermatol. 1958; 30:181-5.

28. Gisondi P, Tessari G, Conti A, Piaserico S, Schianchi S, Peserico $A$, et al. Prevalence of metabolic syndrome in patients with psoriasis: a hospital-based casecontrol study. Br J Dermatol. 2007; 157:68-73.

29. Cohen AD, Sherf M, Vidavsky L, Vardy DA, Shapiro J, Meyerovitch J. Association between psoriasis and the metabolic syndrome. A cross-sectional study. Dermatol. 2008; 216:152-5.

\begin{tabular}{|c|c|c|c|}
\hline \multicolumn{4}{|c|}{ AUTHORSHIP AND CONTRIBUTION DECLARATION } \\
\hline Sr. \# & Author(s) Full Name & Contribution to the paper & Author(s) Signature \\
\hline 1 & Sehrish Aftab & & $£$ \\
\hline 2 & Mahvish Aftab Khan & $\begin{array}{c}\text { All the authors have } \\
\text { contributed equally to data }\end{array}$ & Mehwish \\
\hline 3 & Nadia Shams & $\begin{array}{l}\text { collection, methodology, } \\
\text { analysis, discussion, write up }\end{array}$ & \\
\hline 4 & Sumaira Abdullah & and literature review. & Sumane: \\
\hline 5 & Furquana Niaz & & \\
\hline
\end{tabular}

